\title{
CORPO E PALAVRA: GRUPO TERAPÊUTICO PARA PESSOAS COM TRANSTORNOS ALIMENTARES
}

\author{
Daniel Magalhães Goulart \\ Manoel Antônio dos Santos"
}

\begin{abstract}
RESUMO. Transtornos alimentares constituem relações problemáticas com a alimentação e a imagem de si. Seu tratamento deve contemplar múltiplas estratégias, inclusive a abordagem grupal. Este estudo teve como objetivos desenvolver reflexões sobre a grupoterapia com pessoas com transtornos alimentares atendidas em serviço especializado e investigar a dinâmica psicológica dos pacientes atendidos, a partir de ressonâncias contratransferenciais. Foram analisados registros de observação anotados em diário de campo ao longo de 21 encontros grupais consecutivos. O material foi submetido à análise de conteúdo na modalidade temática. Os resultados foram estruturados em três eixos temáticos: vivências impactantes mobilizadas no contato com os pacientes; demanda de ajuda dos pacientes para encontrarem as palavras perdidas, como via de acesso à representabilidade dos afetos elididos do espaço mental pela operação de desafetação; sentimentos contratransferenciais vivenciados pelo pesquisador. Foram discutidas as implicações para o tratamento, visando à busca de estratégias capazes de proporcionar um ambiente terapêutico que facilite a integração psicossomática.
\end{abstract}

Palavras-chave: Psicoterapia de grupo; distúrbios do ato de comer; medicina psicossomática.

\section{BODY AND WORD: THERAPEUTIC GROUP FOR PEOPLE WITH EATING DISORDERS}

\begin{abstract}
Eating disorders characterize problematic relationship with eating and self image. Treatment should include multiple strategies, including the group approach. This study aimed to: present reflection on the dynamics of group therapy for eating disorder patients attended at a specialized service and investigate the patients' psychological dynamics, based on the countertransferential resonances the researcher experienced. Observation records in a field diary were analyzed, related to 21 consecutive group meetings. The material was submitted to thematic content analysis. The results were structured in three thematic axes: impacting experiences mobilized in contact with patients; patients' demand for help to find the words lost, as a way to access the representability of the feelings elided from the mental space through the unaffectedness operation; countertransferential feelings experienced by the researcher. The implications for treatment were discussed, with a view to seeking strategies that enhance a therapeutic environment that facilitates psychosomatic integration.
\end{abstract}

Key words: Group psychotherapy; eating disorders; psychosomatic medicine.

\section{CUERPO Y PALABRA: GRUPO TERAPÉUTICO EN LOS TRASTORNOS DE ALIMENTACIÓN}

RESUMEN. Trastornos alimentarios caracterizan relaciones problemáticas con la alimentación y con la auto imagen. El tratamiento debe incluir múltiples estrategias, incluyendo la aproximación grupal. Los objetivos de este estudio fueron: presentar reflexiones acerca de la dinámica de la terapia de grupo de personas atendidas en un servicio especializado e investigar su dinámica psicológica, a partir de las resonancias contratransferenciales. Fueron analizados registros de observación anotados en diario de campo, a lo largo de 21 encuentros grupales consecutivos. El material fue sometido al análisis de contenido temática. Los resultados fueron estructurados en tres ejes temáticos:

Mestrando pela Faculdade de Educação da Universidade de Brasília (FE-UnB), Psicólogo pela Universidade de São Paulo e Bacharel Especial em Pesquisa pelo Departamento de Psicologia da Faculdade de Filosofia, Ciências e Letras de Ribeirão Preto da Universidade de São Paulo (FFCLRP-USP).

\# Doutor em Psicologia Clínica pela Universidade de São Paulo, com Livre Docência em Psicoterapia Psicanalítica pela Universidade de São Paulo, campus Ribeirão Preto. Atualmente, é Professor Associado da Faculdade de Filosofia, Ciências e Letras de Ribeirão Preto (FFCLRP-USP). 
vivencias impactantes movilizadas en el contacto con los pacientes; demanda de ayuda para encontrar las palabras perdidas, como vía de acceso a la representabilidad de los afectos elididos del espacio mental por la desafectación; sentimientos contratransferenciales. Fueron discutidas implicaciones para el tratamiento, con el fin de buscar estrategias que promuevan ambiente terapéutico que facilite la integración psicosomática.

Palabras-clave: Psicoterapia de grupo; trastornos de la ingestión de alimentos; medicina psicosomática.

Os transtornos alimentares (TAs) configuram relações problemáticas com a alimentação e a imagem de si, as quais podem acarretar sérios problemas de saúde, inclusive, expor a pessoa acometida ao risco de morte. De acordo com Morgan, Vecchiatti e Negrão (2002), os TAs apresentam etiologia multifatorial, ou seja, são determinados por uma diversidade de fatores que interagem entre si de modo complexo, para produzir e, muitas vezes, perpetuar o quadro psicopatológico.

As expressões psicopatológicas mais recorrentes dos TAs são anorexia nervosa (AN) e bulimia nervosa (BN). De acordo com Nunes, Appolinario, Galvão e Coutinho (2006), a AN é caracterizada por uma busca incansável pela magreza, seguida de redução de peso e sua manutenção abaixo do normal por processos inadequados de controle da massa corporal, levando à desnutrição grave, enquanto na BN ocorre a ingestão descontrolada de uma quantidade imprópria de alimentos, que não visa somente a saciar uma sensação de fome inadequada, mas atende a uma série de estados emocionais ou situações estressantes. Em geral, os momentos de compulsão alimentar são seguidos por episódios purgativos utilizados para o controle de peso, como vômitos autoinduzidos, dietas, exercícios físicos em excesso e uso abusivo de medicamentos como laxantes, diuréticos e inibidores de apetite. Nesses transtornos, o corpo aparece como via privilegiada de expressão do sofrimento psíquico, havendo relativa dissociação da integração funcional da psique e do soma - fenômeno frequentemente associado aos chamados transtornos psicossomáticos (Ferreira, 2010; Ramalho, 2005).

Peres e Santos (2010) argumentam que o termo psicossomática deve ser empregado, atualmente, como substantivo para nomear uma disciplina científica que tem como principal pilar a hipótese da existência de uma unidade funcional entre o somático e o psíquico. Assim, ganha relevância a clássica tese de Groddeck (1920/1992), de que toda doença orgânica é igualmente psíquica, e vive-versa. Este autor considera, como um princípio central, a ideia de que a intervenção psicoterapêutica se aplica a qualquer tipo de enfermidade. Nesta lógica, a doença corresponderia a uma solução, ainda que problemática, engendrada pelo indivíduo na tentativa de lidar com seus conflitos inconscientes. Tal visão integradora do ser humano demanda alternativas de apreensão teórica que não se limitem à leitura do corpo como organismo (Teixeira, 2006).

Em concordância com Winnicott (1988), considera-se, neste estudo, que o alcance da unidade psique-soma é um dos aspectos essenciais do amadurecimento pessoal. Esse processo inicia-se desde o nascimento e desdobra-se por toda a vida. Segundo o autor, os distúrbios do psicossoma seriam alterações do funcionamento corporal associadas a estados da psique, não sendo possível supor intensa relação entre essas dimensões (soma e psique), já que esse vínculo estaria comprometido, ou até mesmo, rompido. Neste sentido, o transtorno psicossomático, ao mesmo tempo em que está relacionado a uma dissociação ou tendência à cisão, traduz, paradoxalmente, um processo de tentativa de restabelecer essa íntima relação.

Segundo McDougall (1991), no processo de somatização os afetos são "ejetados" do aparelho mental e não geram sintomas psicóticos, como delírios ou alucinações, mas se perdem ou se desvanecem sem que haja qualquer tipo de compensação psíquica, com a consequente tendência a reduzir-se a pura expressão somática.

A incidência de transtornos psicossomáticos é significativa na clínica psicológica contemporânea. Teixeira (2006) lembra que, nesses transtornos, o corpo é afetado em sua realidade orgânica e funcional, de modo que essas manifestações podem ser capturadas por exames laboratoriais, imagéticos ou clínicos. A emergência do corpo na clínica psicológica contemporânea situa o somático "como veículo e plataforma do sofrimento, deixando-se falar através das queixas somáticas e da ausência de implicação do sofrente na história do corpo doente" (p. 22). No entanto, a autora ressalta que essas somatizações nem sempre são da mesma ordem, uma vez que há uma pluralidade de expressões nesses fenômenos. Neste sentido, podemos pensar nas manifestações psicossomáticas clássicas, como asma, doenças dermatológicas ou hipertensão, mas também nos transtornos alimentares, na drogadição e no uso abusivo de cirurgias plásticas, apenas para mencionar alguns exemplos, como condições passíveis de serem caracterizadas como psicossomáticas (Ferreira, 2010). Nessa diversidade, também se discute o caso peculiar das somatizações histéricas, que, embora possam paralisar, anestesiar ou cegar o corpo, não afetam o 
"real do corpo" (p. 23). Assim, enquanto o paciente histérico fala por meio de seu corpo, o psicossomático sofre no corpo (Myssior, 2007). Por isso, acredita-se que a desordem psicossomática, pelo menos a princípio, é vazia de significação.

A associação entre TAs e transtornos psicossomáticos não é recente, tendo sido proposta pela primeira vez em 1694, por Richard Morton (Hercovici, \& Bay, 1997). Ferreira (2010) argumenta que, tanto na anorexia como na bulimia, encontramos a dissociação referente aos transtornos psicossomáticos, entre a psique e o soma. $\mathrm{Na}$ AN essa dissociação muitas vezes leva a pessoa a se manter em um estado de escassez alimentar incompatível com as condições que o corpo demanda para continuar vivendo; já na BN, é a ingestão abusiva de alimentos, seguida por práticas purgativas, que seria a manifestação dessa dissociação. Esses transtornos representam, ao mesmo tempo, o risco de consequências somáticas drásticas e a tentativa (ainda que problemática) de não perder totalmente a integração psicossomática.

No presente estudo, a adoção dessa perspectiva teórica se justifica por contribuir para lançar luz às manifestações sintomáticas que marcam esses quadros psicopatológicos que tanto desafiam os profissionais de saúde em sua prática clínica, sem menosprezar, evidentemente, a relevância de outras vertentes compreensivas.

Como os TAs apresentam quadros graves e complexos, seu tratamento deve abordar estratégias de múltiplas naturezas. Neste sentido se faz necessário um trabalho articulado de uma equipe multidisciplinar que inclua um profissional de Psicologia. A intervenção psicológica se dá em diversos âmbitos, exigindo, por via de regra, a aplicação combinada de recursos complementares, como psicoterapia individual, atendimento de apoio ambulatorial, grupo de apoio com familiares e grupo terapêutico com pacientes (Abreu, \& Filho, 2004; Santos, 2006).

Considerando-se os propósitos do presente trabalho, o foco é direcionado ao contexto do grupo terapêutico, considerado como uma das táticas que compõem uma estratégia de tratamento mais ampla que, necessariamente, deve incluir intervenções variadas. Na experiência de grupoterapia, com o apoio dos terapeutas, os participantes podem refletir sobre suas emoções e condutas a partir de um novo e diferente vértice, gerado pelas interações no espaço vital do grupo, no sentido de criar possibilidades de mudança em seus padrões relacionais (Santos, 2006).

Diversas são as perspectivas de investigação no universo dos TAs. Um notável destaque é dado aos estudos que se dedicam a investigar: (1) aspectos relativos ao transtorno, como diagnóstico, evolução e prognóstico (Miranda, 2007; Morgan et al., 2002), tratamento (Abreu, \& Filho, 2004), inclusive do ponto de vista da dinâmica psíquica do paciente (Miranda, 2005; Santos, 2006; Tierney, 2008); (2) o impacto do transtorno sobre a qualidade de vida da pessoa acometida e dos familiares, bem como o modo como a família se (des)organiza para lidar com o problema, o estresse e a sobrecarga emocional decorrentes dos cuidados e exigências do tratamento (Espíndola, \& Blay, 2009; Sim et al., 2009). Não obstante, de acordo com Rabinor (2009), poucos estudos têm sido dedicados a investigar o impacto da prática clínica sobre a vida do profissional de saúde que atua nesse cenário. Mais especificamente, não foram encontrados na literatura estudos que focalizem as percepções do psicoterapeuta sobre o grupo terapêutico.

Sabe-se que, na trajetória do tratamento, não apenas o paciente pode entrar em contato com situações que mobilizam cargas intensas de ansiedade, mas também o psicoterapeuta, inevitavelmente, revisita aquilo que está recalcado em sua constituição psíquica. Essa ressonância subjetiva, se bem aproveitada e elaborada, pode se constituir em oportunidade para crescimento e renovação da motivação do próprio profissional (Dana \& Satir, 2009). Neste sentido, considera-se relevante a incorporação das vivências contratransferenciais do terapeuta na análise da dinâmica grupal.

Tendo em vista esses apontamentos, este estudo teve como objetivo geral desenvolver algumas reflexões sobre a dinâmica da psicoterapia de grupo de pacientes com TA atendidos em um serviço especializado, tendo como fio condutor a experiência do pesquisador como observador do grupo. Como objetivo específico, investigou a dinâmica psicológica dos pacientes a partir das ressonâncias contratransferenciais vivenciadas pelo pesquisador.

\section{MÉTODO}

O estudo é descritivo do tipo exploratório e interpretativo, de abordagem qualitativa (Bogdan \& Biklen, 1994). O princípio metodológico que fundamentou a elaboração desta pesquisa foi o estudo de caso. De acordo com Yin (2005), o estudo de caso pode ser utilizado para descrever uma intervenção e o contexto da vida real em que os fatos ocorrem. Dessa maneira, enquanto estratégia de pesquisa, possibilita contribuir para o conhecimento de fenômenos individuais, organizacionais, políticos e de grupos, agregando um saber produzido em contextos que não são preparados especificamente para pesquisa, como é o caso dos grupos terapêuticos oferecidos em serviços de saúde. 
Selecionou-se como caso a ser investigado um grupo terapêutico para pacientes com diagnóstico de TA, desenvolvido em um serviço ambulatorial de um município do Interior Paulista. Assim, p cenário da presente investigação foi o grupo terapêutico, constituído pelo coordenador, uma co-coordenadora, uma observadora silente, o pesquisador e os pacientes - estes, de quatro a cinco participantes por sessão.

Por se tratar de uma investigação empreendida no contexto de uma intervenção clínica, os critérios de inclusão para o presente estudo coincidem com os adotados para a composição do grupo, a saber: preenchimento dos critérios diagnósticos do DSM-IV para $\mathrm{AN}$ e BN; faixa etária a partir de 14 anos, sem limite máximo; aceitação, por parte do paciente, da estrutura de funcionamento do grupo; e disposição para comparecer às sessões pelo menos nos retornos ambulatoriais. O grupo era aberto, isto é, os participantes eram livres para comparecerem semanalmente, sem agendamento prévio. Os pacientes eram fortemente encorajados a participar, mas essa participação não era compulsória, por se entender que a possibilidade de estar em grupo é uma conquista, muitas vezes, precedida de um período de preparo e fortalecimento interior para enfrentar os desafios de se expor na situação grupal.

Trata-se de um grupo homogêneo quanto ao diagnóstico, que se desenvolve em sessões semanais de 90 minutos. De modo geral, o objetivo da estratégia grupal é tirar proveito dessa situação, na qual se tem certo nível de heterogeneidade na relativa homogeneidade que é oferecida pela circunstância de se estar em seguimento em um serviço especializado no tratamento de TAs. Desse modo explora-se o potencial terapêutico decorrente do encontro das diferenças individuais e da diversidade de experiências dos participantes em um contexto de relativa uniformidade, garantida - mas só até certo ponto pelo diagnóstico descritivo comum (Santos, 2006).

Embora os observadores não participem ativamente no decorrer da sessão, no final de cada encontro são convidados pelo coordenador a compartilharem com os participantes suas impressões acerca da experiência. Dessa maneira, um canal de comunicação é aberto entre os observadores e o restante do grupo.

As sessões ocorreram em uma sala apropriada nas dependências da instituição hospitalar. O estudo foi desenvolvido no período de fevereiro a julho de 2010. Foram observadas 21 sessões. O material clínico foi extraído dos registros do diário de campo do pesquisador. Os dados foram sistematizados a partir das anotações realizadas logo após o término de cada encontro grupal. Esses dados foram submetidos à análise de conteúdo na modalidade temática (Bogdan
\& Biklen, 1994). São três as etapas do processo de análise: (1) pré-análise, que consiste em leituras exaustivas para organização do material e sistematização das principais ideias; (2) descrição analítica, que corresponde à categorização dos dados em unidades de registros; e (3) interpretação referencial, que é uma interpretação dos achados com base na abordagem teórico-conceitual adotada.

Para a sistematização do material, apresentação e análise dos aspectos selecionados, foram estruturadas narrativas clínicas, nas quais se buscou privilegiar os excertos de falas e experiências que colocassem em relevo os fenômenos emergentes, tais quais foram vivenciados e apreendidos na perspectiva do pesquisador.

A análise e interpretação dos resultados foram fundamentadas na psicossomática psicanalítica, assumida no presente estudo como guia teóricoconceitual útil para a compreensão da dinâmica de funcionamento dos pacientes em grupo terapêutico (McDougall, 1984, 1991, 1994). O projeto recebeu aprovação do Comitê de Ética em Pesquisa da instituição hospitalar e os participantes concordaram com a realização do estudo nas condições naturalísticas em que foi proposto, mediante assinatura do Termo de Consentimento Livre e Esclarecido. Para preservar o anonimato, os nomes próprios utilizados neste estudo são fictícios.

\section{RESULTADOS E DISCUSSÃO}

Os resultados foram estruturados em três eixos temáticos, a saber: 1) Vivências impactantes mobilizadas no contato com os pacientes; 2) Demanda de ajuda dos pacientes para encontrarem as palavras perdidas, como via de acesso à representabilidade dos afetos elididos do espaço mental pela operação de desafetação; e 3) Sentimentos contratransferenciais vivenciados pelo investigador.

\section{Vivências impactantes mobilizadas no contato terapêutico}

A primeira sessão do grupo, após o recesso de fim de ano do serviço, ocorreu na quinta semana de 2010. A inserção do pesquisador e da estagiária no grupo terapêutico, na posição de observadores, a princípio 
causou desconforto aos pacientes, embora eles estivessem habituados à troca de observadores a cada início de ano. Isso pôde ser percebido a partir de algumas falas que, conquanto não direcionadas explicitamente aos novos integrantes, expressaram ansiedade diante do novo, pela insegurança experimentada com a mudança do setting terapêtico.

Uma das participantes expressou certo incômodo com a presença do que ela qualificou de intrusos no grupo, utilizando-se da metáfora "alienígenas". O mal-estar produzido pôde ser explicitado com a ajuda dos coordenadores do grupo e sua elaboração foi facilitada pelo fato de os pacientes já se constituírem como um grupo. Desse modo, o vínculo já estabelecido entre pacientes e coordenadores pôde servir de sustentáculo para o enfrentamento dos sentimentos ameaçadores desencadeados pela inserção de novos componentes no grupo. Não obstante, se por um lado isso atesta uma dinâmica que favorece as trocas entre as pessoas no contexto interacional do coletivo grupal, por outro, os desdobramentos dessa inserção causaram impacto intenso no pesquisador, haja vista que os conteúdos que emergiam amiúde nas falas delineavam os novos integrantes como estranhos e invasores. Esse clima grupal matizou o estabelecimento do vínculo inicial entre pacientes e observadores.

Neste contexto, logo na primeira sessão de que participou, o pesquisador pôde desenvolver certa percepção, ainda que incipiente, do funcionamento do grupo. Algo que desde as primeiras falas pôde ser percebido foi o movimento de constante troca de papéis, no qual os pacientes se engajavam no desenrolar da sessão, alternando entre a posição de quem necessita receber ajuda e a de quem a oferece ao outro participante. Esses remanejamentos ficaram explícitos em uma situação específica. Em um dado momento, uma paciente - Bárbara, com 17 anos -, pareceu sucumbir à angústia:

\begin{abstract}
"Eu perdi minha mãe com 13 anos e meu pai morreu logo depois também em um acidente de carro. Foi quando eu comecei a ficar doente. Eu não queria saber de comer, nada, nada. Daí eu fui só emagrecendo. Eu mesma não percebia o tanto. Olhava no espelho $e$ ainda me achava gorda, sabia que eu podia ir além. Até que eu, com 1,78 m, cheguei a ficar com $33 \mathrm{~kg}$ e me olhei no espelho. Nesse momento, eu vi um cadáver e pedi pra minha madrinha que pelo amor de Deus me internasse, porque eu não conseguia sair daquilo sozinha."
\end{abstract}

Em seguida, o único paciente masculino do grupo, Luan, de 16 anos, emendou com outro relato denso, permeado por um sentimento de raiva que se presentificava no conteúdo narrado, mas não em sua modulação afetiva, que se mantinha inalterada:

\begin{abstract}
"Na minha casa está tudo um inferno! Eu odeio meu pai, odeio com todas as minhas forças. Ele não foi meu pai a vida inteira e agora quer ser. Mas ele não entende que não dá mais. Fica falando que é pra eu comer pelo menos um pouquinho. Quem ele acha que é? Eu até como, mas daí eu vou vomitar e nem vou dar descarga que é pra ele ver."
\end{abstract}

Bárbara, então, dirigiu a palavra a Luan:

"Luan, todo mundo tem problemas com a família. Eu mesmo, quando meus pais eram vivos, tinha muitas coisas de que eu não gostava. Mas você ainda tem eles e não os perdeu pra saber como é ruim. Você não acha que isso tudo pode ser diferente? Não depende também de você?"

Bárbara, nesse momento, consegue se posicionar em outro papel e se percebe como alguém em condições de oferecer apoio, compreensão e até sugestões a Luan, valendo-se de sua sofrida experiência de orfandade.

Esse processo de auxílio recíproco proporciona benefício às duas partes e atua positivamente no plano da autoestima, tanto de quem está oferecendo suporte como de quem o está recebendo. Muitas vezes as sugestões refletem aspectos importantes inclusive dificuldades - da própria pessoa que as oferece. Quem as recebe, ao se sentir ouvido e acolhido em seu sofrimento, vivencia o sentimento agradável de se integrar no grupo, de ser aceito, valorizado e respeitado como ser humano. Por outro lado, ao reconhecer no outro a presença de tristezas, alegrias e de outros sentimentos que também lhe são próprios, a percepção de solidão é arrefecida e aumenta a esperança de que é possível tolerar a frustração sem se desintegrar, o que representa um passo fundamental para a conquista do insight que facilita a mudança.

No grupo, as posturas dos integrantes não se mantêm passivas, a ponto de, em certas situações, tocarem-se fisicamente, por meio de gestos carregados de afeto e empatia. Em uma sessão posterior à narrada acima, uma paciente manifestou seu desejo de abraçar outra que acabara de expor sua fragilidade emocional, tendo sido encorajada pelo coordenador do grupo a expandir seu gesto espontâneo, o que acabou acontecendo em um clima de enlevo e comunhão.

Assim, as agressões frequentemente autoinfligidas pelos pacientes com TA parecem momentaneamente atenuadas ao se valerem de suas mãos e braços para se 
entrelaçarem em uma busca concreta por holding e mutualidade. Desse modo, os mesmos corpos, habitualmente utilizados como via direta de expressão dos conflitos gerados por afetos antagônicos (os quais assumem muitas vezes o caráter de autodestruição), são agora utilizados como veículos para uma nova experiência: a delicadeza do toque e da carícia, que transmitem aconchego e ternura. Estabelecem-se, assim, novos significados, que são outorgados ao corpo, ao outro e a quem os percebe, além de novas vias de acesso à sensorialidade.

Pôde-se perceber que, a partir de contato com o sofrimento psíquico dos pacientes com $\mathrm{AN}$ e $\mathrm{BN}$, muitas vezes, sentimentos de abandono e desamparo vivenciados em suas histórias de vida são, pelo menos momentaneamente, aplacados com gestos simples no espaço vital do grupo. Talvez poucas pessoas tenham conseguido traduzir em palavras esses grandes momentos ínfimos, que instauram verdadeiras epifanias, com a mesma precisão que foi alcançada por Rosa (2006/1956): "Só se pode viver perto de outro, e conhecer outra pessoa, sem perigo de ódio, se a gente tem amor. Qualquer amor já é um pouquinho de saúde, um descanso na loucura.” (pp. 438-439).

Até mesmo se dispor a compartilhar um momento de silêncio pode representar uma forma de se estar com e para o outro. Assim, o silêncio, frequentemente interpretado na literatura como certo tipo de resistência expressa, seja por timidez de se expor ao grupo, seja por desinteresse diante de determinado assunto, pode assumir outros sentidos e se transformar, por exemplo, em uma manifestação compartilhada de profunda sensibilização diante da dor do outro, exposta nas fronteiras protegidas do espaço grupal. Nessa ótica, o grupo parece funcionar como invólucro protetor e o não dito ganha destaque e se torna pilar fundamental no processo de comunicação humana.

\section{Em busca das palavras perdidas}

Para além das potenciais riquezas do silêncio compartilhado, em outras ocasiões o que é dito no grupo ganha sentido em processos sumamente criativos. Por vezes, em determinada fala, alguma representação do universo psíquico do paciente se revela por meio do uso de metáforas, em um jogo aberto e construtivo da fantasia. A seguinte vinheta clínica ilustra a dinâmica desse processo:

Giovana: As coisas na vida são como o meu pai diz: tem que matar um leão por dia, né.

Coordenador: E o que seria esse leão de que a Giovana fala, hein? Vamos ver se a gente descobre.
Délia: Acho que o leão está dentro da gente, né? É algo que a gente tem que lidar com a gente mesmo.

Coordenador: Eu penso que isso não é algo fácil de ser feito. A gente quer dar conta dele, mas ao mesmo tempo tem medo. $O$ que vocês acham?

Luan: Eu acho que a gente tem que lutar com o leão, mas a gente tem que se proteger dele também, senão ele acaba com a gente.

(Pausa)

Co-coordenadora: Luan, para se proteger a gente precisa de algo como uma grade de ferro bem resistente, e ao mesmo tempo é necessário que essa gaiola permita que a gente viva. Senão a gente fica preso e vai morrendo aos poucos.

(Silêncio por alguns instantes)

Luan: Eu sei qual é o meu leão. Eu sei do que eu tenho que me proteger e com o que eu tenho que lutar. Mas eu não quero falar disso agora aqui no grupo.

Coordenador: É um direito legítimo que lhe cabe, só falar quando você se sentir à vontade.

Depois dessa fala, o grupo tratou de outros conteúdos emergentes. Contudo, de forma recursiva, a metáfora do leão reaparecia no desenrolar da sessão, sob as mais variadas formas e acepções. Ao chegar o fim da sessão, os observadores foram convidados a compartilhar com o restante do grupo suas impressões acerca da sessão daquele dia. Um dos observadores retomou, em sua fala, a metáfora leonina e a enriqueceu com novos elementos:

"Eu fiquei pensando na imagem do leão, que
foi sendo trabalhada ao longo da sessão, e
esse leão, a todo o momento, foi tratado
como sendo externo a nós, como algo a ser
temido e com o qual devemos lutar. Mas o
que eu fiquei pensando é que, pelo fato de o
leão estar dentro de nós, de certa forma ele
nos constitui, o que nos faz lutar contra nós
mesmos. Ao invés de espantar ou vencer o
leão, matando o animal, talvez devêssemos
aprender a lidar com a fera de uma forma
diferente. De um modo que a gente não
precise de grades tão fortes e que também
não precisemos morrer aos poucos."

Como pode ser visto, uma vez compartilhada, a metáfora deixa de ser uma representação individual e adquire a dimensão de uma construção coletiva. É como uma tela que vai sendo gradualmente pintada 
pelos movimentos de diversas mãos: cada participante oferece sua pincelada, imprimindo sua marca autoral na produção de sentidos. Até mesmo o silêncio é contribuição requintada, uma vez que pode significar uma parcela de trabalho meditativo. Assim, dos pensamentos se faz forma e dos sentimentos se fazem cores. Ao final, uma obra foi produzida: a sessão terapêutica.

De acordo com Bleger (1993), o psicoterapeuta não precisa necessariamente fazer algo para que se estabeleça o processo dialético do pensar, pois ele é espontâneo; entretanto, há muito que fazer para remover as barreiras e bloqueios que impedem seu pleno funcionamento. Uma profícua maneira de facilitar a retirada dos processos obstrutivos no grupo é fazer um uso apropriado da atividade interpretativa. Como expressa sensivelmente Miranda (2007), a palavra interpretativa instaura a conexão e repara o hífen que liga a psique ao soma e, ao mesmo tempo, retira a separação do corpo oral, fertilizando e abrindo frentes para novas descobertas. De acordo com Campos (2006), enquanto o desejo visa à satisfação, a palavra oferece a possibilidade de espera. Desse modo, os processos de tensão ou de dor que se estabelecem no corpo podem ser atenuados pela palavra que advém de um outro, de maneira a permitir que a frustração seja tolerada, a dor psíquica seja humanizada e as percepções, finalmente, pensadas. A partir da próxima vinheta clínica pode-se apreender esse processo de maneira mais clara.

Marília, que normalmente frequenta as sessões do grupo somente nas datas pré-agendadas para retorno às consultas individuais com o nutrólogo, o nutricionista e o psiquiatra, compareceu ao grupo, para surpresa de todos, em uma data diferente desse retorno. Ela havia tido outro tipo de atendimento médico no hospital na parte da manhã, não relacionado ao tratamento do TA, e havia esperado cerca de três horas para o início da sessão do grupo terapêutico. Como reside em uma cidade distante e viaja com um carro da prefeitura local, ficou evidenciado o esforço que fizera, além da longa espera, quando ela contou que teve de convencer o motorista a esperá-la até o fim da sessão do grupo terapêutico, alegando ter outra consulta médica na segunda parte do dia. Ao iniciar a sessão, o coordenador chamou a atenção do grupo para o fato inusitado. Ele acabara de conversar com Marília a respeito.

Nesse sentido, o coordenador disse:

"Hoje estamos contando com a presença especial de Marília, que está vindo em um horário que não é o seu habitual. Você quer falar para o grupo por que você se empenhou tanto para estar aqui?"
Marília responde ao grupo, abrindo um sorriso enternecido:

"É que eu estava com saudades de todo mundo. Quando eu vi o Marcos (coordenador), meu olho até encheu de lágrima e eu pensei: "Que bom que eu tô aqui”. É que vocês são mesmo a minha família, os amigos que eu tenho, e cada um aqui está dentro do meu coração."

Marília estava visivelmente sensibilizada e, ao mesmo tempo, mantinha um olhar distanciado em relação ao que estava se passando ali, apesar do relato emocionado que ofereceu às pessoas do grupo. $\mathrm{O}$ coordenador, captando outros elementos que possivelmente estavam por trás da fala de júbilo da paciente, interveio:

Coordenador: "Está difícil aguentar a barra l, na sua cidade, sozinha, não é, Marília?"

Emocionada, Marília desabou a chorar e disse:

"Tá muito difícil! Todo dia eu acho que eu não vou aguentar. Tem dia que tudo o que eu quero na vida é morrer. Daí eu falo isso e minha filha me responde: "Mãe, no dia em que você morrer, eu quero que o meu caixãozinho esteja lá do lado, eu me mato junto, porque eu não consigo ficar aqui sem você." E nesses momentos eu lembro da internação que eu tive aqui. Nossa, era tão bom... Eles cuidavam de mim, me davam comida... (pausa) Era tão bom quanto colo de mãe. Tudo o que eu queria era ficar lá de novo."

Pelo relato de outras pacientes que frequentam esse grupo terapêutico, percebe-se que a internação, em geral, é um processo vivenciado de maneira traumática, um momento muito difícil para a pessoa que a vivencia; porém a hospitalização integral é sentida de modo completamente diferente por Marília, que em seu relato comovente chega a solicitar que seja novamente internada. Então o coordenador diz:

\footnotetext{
"A internação é como o colo da mãe de que você sente falta, ou que você não teve. E hoje o que eu vejo é que o grupo está sendo como uma grande mãe também, disponível para você, como esse colo que você procura e não acha em sua vida."
}

Nesse momento Marília desatou a chorar, a ponto de mostrar dificuldade momentânea de respirar. O grupo permaneceu em silêncio por alguns instantes, nitidamente impactado e, de certo modo, vivenciando também aquele momento de dor. 
No caso de Marília, como argumenta Teixeira (2006) em discussão acerca dos transtornos psicossomáticos, "a construção de discursos pelo sujeito sobre sua dor de existir mostra-se suprimida, padecendo o corpo em sua concretude" (p. 26). Há, então, um árduo desafio colocado ao fazer clínico, na medida em que uma de suas funções fundamentais nesse contexto é tornar legível o sujeito-corpo-doença em um jogo simbólico que não se reduz ao exercício de escrutínio do biológico. Pode-se dizer, ainda, que muitas vezes pacientes como Marília procuram cúmplices em sua dor. Assim, o que pode ser oferecido a ela são possibilidades de conviver com a incontrolável angústia e mal-estar, buscando alternativas de repensar a si mesma na tentativa de não tornar insuportável a já tão dolorosa experiência de existir.

Ao discorrer acerca de processo de adoecimento nos TAs, Miranda (2005) focaliza possíveis falhas ocorridas precocemente no processo identificatório, as quais se desdobram nas questões de identidade, áreas do desenvolvimento que ficaram sem representação e assim foram impedidas de evoluir. São mentes que burlam a possibilidade de pensar a dor. De acordo com a autora, esses elementos seriam sinais dos nossos tempos, marcados por sofrimentos que se expressam no nível do corpo. O vazio representacional gera aparelhos psíquicos impermeabilizados, incapazes de abrigar áreas de representabilidade do afeto. Neste sentido, existiriam certas "representações-limite" circundando em todo o seu perímetro o abismo do não saber:

Representações-limite que aqui poderiam coincidir com as imagens acústicas das palavras, a gradual aquisição de sentido a partir das lembranças de palavras ouvidas, as sensações convocadas por elas, estimuladas também pelos ensaios escritos que vão se transformando em falas associativas e finalmente nos afetos (Miranda, 2007, p. 33).

A partir dessa metáfora, talvez fique mais clara a necessidade de achar as palavras perdidas, como via de encontro do afeto deslocado, na busca do sentido de si. Tais ideias encontram sustentação teórica no conceito proposto por McDougall (1984) de desafetação. Trata-se de um processo que envolve o rompimento do indivíduo com seus próprios sentimentos e que o leva, por consequência, a encontrar dificuldades em apreender contrastes emocionais e discriminar não só os seus afetos, mas também os das demais pessoas com as quais convive.

Neste sentido, Peres e Santos (2010) argumentam que a diluição das fronteiras psíquicas tem seu correlato no colapso dos contornos corporais, que é impulsionado pela regressão a um estágio de indiferenciação primária em que se regride ilusoriamente à vivência de que existem em um único corpo dois seres vivos. Nas palavras dos autores, "essa condição, por manter-se às custas (sic) da pulverização das emoções, enseja a tradução somática de uma história sem palavras, a qual, privada de significado simbólico, ocupa o lugar de sonhos malogrados" (p. 106). Assim, os atos passam a ser utilizados como única possibilidade de escoamento das tensões, em detrimento de qualquer atividade provida de valor simbólico (Peres, 2006).

O grupo é espaço ideal para essa empreitada de traduzir experiências e conferir-lhes uma representação simbólica, na medida em que vozes são distribuídas e o pensamento se articula como uma construção de todos, a partir da matéria-prima comum que é o sofrimento diante do que ainda não foi elaborado. Pode ser apenas um integrante a enunciar algo, mas são vários a escutarem e, principalmente, a compartilharem, pois estão juntos ao se empenharem na aproximação e elaboração do que até então não podia ser reconhecido, porque não tinha nome.

\section{Sentimentos contratransferenciais vivenciados pelo pesquisador}

Segundo Laplanche e Pontalis (1982/2001), a contratransferência representa o "conjunto das reações inconscientes do analista à pessoa do analisando e, mais particularmente, à transferência deste" (p. 102); porém esse conceito carrega significativa transformação na história da psicanálise, de modo que tal fenômeno deixou de ser entendido, como no início, apenas como obstáculo, para ser considerado, posteriormente, como poderoso instrumento analítico (Sato, 2010). Neste sentido, Andréa (2006) argumenta que trabalhar tal tema tendo em vista o contexto grupal é poder pensar no afeto, seja este do indivíduo, do grupo ou do terapeuta. Assim, é necessário que o terapeuta se perceba para então poder perceber o que está sendo dito na sessão, mesmo quando este dizer não se faça na linguagem verbal.

Voltando para o grupo terapêutico analisado, diante de situações tão singulares e dos momentos fecundos ensejados, diversos sentimentos, por vezes muito intensos, foram vivenciados pelo pesquisador: vontade súbita de chorar, desejo de sair da sala durante a sessão, intenso assomo de fadiga e sono. Em outras ocasiões, angústias vivenciadas no decorrer do encontro grupal deram espaço à sensação de peso após o término da sessão, por meio da identificação com os conteúdos emergidos. Em alguns desses momentos ocorreu a sensação de imobilidade, de estar paralisado diante de tanta dor. Nesse processo de sentir-se sitiado - em vez de situado em si mesmo - muitas vezes 
aconteceu a incapacidade momentânea de enxergar o outro como sujeito ativo no processo de adoecimento, e, sobretudo, de percebê-lo como protagonista na mobilização de potenciais recursos facilitadores de seu processo de superação do sofrimento. No grupo sob investigação, ficou clara a importância de os terapeutas desenvolverem a capacidade de deixar-se levar sensivelmente pelo paciente, de modo a aproximar-se de uma compreensão de seus sentimentos por meio de um engate empático no universo emocional de quem sofre. Posteriormente, e de forma não menos importante, ocorreu a retirada estratégica desse lugar provisório que fora ofertado, desfazendo-se o enlace imaginário para que pudesse advir o estranhamento daquilo que ali se processava, de modo a ajudar a pessoa a vislumbrar novas possibilidades e tecer alternativas ao se sentir apoiada pelo grupo. Assim, ganha relevância para a prática terapêutica a aplicação do conceito de dissociação instrumental (Bleger, 1993), essa capacidade de estar "tão longe" e, simultaneamente, "tão perto", sem diluir as fronteiras psíquicas entre o terapeuta e o paciente.

Outro ponto considerado crucial no fazer clínico, evidenciado ao longo das sessões grupais, foi $o$ aumento da capacidade empática diante do sofrimento do paciente. Em investigação acerca dos limites e aplicações do conceito de empatia, Nava (2005) afirma que não se trata apenas das ressonâncias afetivas entre o eu e o outro, mas também da representação explícita da subjetividade do outro. Esse processo foi percebido pelo pesquisador no contexto investigado, até mesmo em contatos fugazes, de poucos segundos. Foram impressões quase imediatas acerca dos estados emocionais dos pacientes. No convívio cotidiano com pessoas que desenvolveram TA, a comunicação, por via de regra, é banhada por concretude e sensorialidade. Neste contexto particular, a linguagem não verbal, expressa no modo de olhar, de se vestir, de se sentar, de se portar e estar diante do outro, muitas vezes é mais impactante e diz mais sobre a pessoa do que suas palavras, especialmente quando estas perderam sua nobre função de articular afeto e representação.

Outro ponto muito interessante do contato com essa prática clínica surgiu no relato de pacientes que frequentavam o grupo havia vários anos, em alguns casos, mais de dez anos. Nesses discursos as conquistas e transformações adquiridas com o decorrer do tempo, bem como os benefícios percebidos na postura de enfrentamento, compareciam em histórias que eram carregadas da dor de existir, mas abrigavam também movimentos rumo ao crescimento, que expressavam desejo de viver, que precisam ser reconhecidos pelo terapeuta. Isso não é pouco para quem vive cada dia como uma luta áspera e renhida pela sobrevivência. Neste sentido, o contato inaugural com o campo configurado pela clínica dos TAs fomentou a curiosidade do pesquisador, fortalecendo o desejo de entrar em contato com o outro no espaço potencialmente transformador do grupo. Como bem disse o escritor Guimarães Rosa (2006/1956), “(...) a vida é mutirão de todos, por todos remexida e temperada" (p. 658).

\section{CONSIDERAÇÕES FINAIS}

A partir das sucessivas sessões de psicoterapia e do gradual envolvimento nos mais diversos acontecimentos desenrolados no palco grupal, percebeu-se que o grupo funcionou como um espaço relacional em que, por meio do contato com o outro, novas alternativas e possibilidades são tecidas para o devir humano. Além disso, mostrou-se como espaço ideal no árduo desafio de traduzir experiências e conferir-lhes uma representação simbólica, na medida em que vozes são distribuídas e o pensamento se articula como construção conjunta. $\mathrm{O}$ paciente, nesse contexto, longe de ser um indivíduo isolado, é considerado como sujeito ativo tanto no processo de adoecimento como na busca dos meios e recursos para dar sentido ao seu padecimento.

O potencial transformador do grupo terapêutico não se encontra exclusivamente nas mãos dos profissionais, tampouco apenas nas mãos de um paciente. Ele pertence ao coletivo, ao espírito de mutirão, que só subsiste pela capacidade do encontro. É no encontro que se adoece e é só pelo encontro que podem ser buscados os meios terapêuticos que conduzirão à cura. Novamente, a sensibilidade do escritor pode nos auxiliar a lançar luz sobre essa travessia, ao dizer que “(...) o mais importante e bonito, no mundo, é isto, que as pessoas não estão sempre iguais, ainda não foram terminadas, mas que elas vão sempre mudando. Afinam ou desafinam. Verdade maior. É o que a vida me ensinou" (Rosa 1956/2006, pp. 24-25).

De fato, com base nas análises elaboradas, podese considerar que mesmo pessoas gravemente adoecidas nunca perdem a capacidade de se transformar. Nessa perspectiva, o TA, comumente considerado um transtorno de curso crônico e incapacitante, não cronifica uma pessoa em suas potencialidades, pois não encerra as alternativas de caminhos possíveis. As pessoas emagrecem e engordam ou, como diz o romancista mineiro, "afinam ou desafinam" no percurso de suas travessias. A ambivalência de uma tentativa de suicídio só pode ser vista pelo grito de socorro que sucede (e certamente antecede) o ato. Vozes roucas que não se calaram e 
que, por isto mesmo, podem se fazer ouvir no grupo, desde que encontrem uma escuta atenta.

As análises elaboradas neste estudo apontam para a necessidade de pesquisas futuras que se debrucem sobre a temática das dinâmicas envolvidas na grupoterapia de pessoas com transtornos alimentares, de modo a possibilitar reflexões e conhecimentos que contribuam para a implementação de estratégias de intervenção mais adequadas para acolher a problemática segundo as necessidades da integralidade em saúde.

\section{REFERÊNCIAS}

Abreu, C. N., \& Filho, R. C. (2004). Anorexia nervosa e bulimia nervosa: a abordagem cognitivo-construtivista de psicoterapia. Revista de Psiquiatria Clínica, 31(4), 177-183.

Andrea, M. A. (2006). Transferência e contratransferência: o sentir como instrumento de trabalho no processo grupal. Revista da SPAGESP, 7(2), 51-58.

Bleger, J. (1993). Temas em Psicologia: entrevista e grupos (R. M. M. de Morais, Trad.). São Paulo: Martins Fontes.

Bogdan, R. C., \& Biklen, S. K. (1994). Investigação qualitativa em educação: uma introdução à teoria $e$ aos métodos. Lisboa: Porto Editora.

Campos, M. R. B. (2006). Distúrbios da imagem do corpo na contemporaneidade. In. Anais do II Congresso Internacional de Psicopatologia Fundamental e VIII Congresso Brasileiro de Psicopatologia Fundamental de 2006. Recuperado em 29 de agosto, 2010, de http://www.fundamentalpsychopathology.org/anais 200 6/2.4.1.htm

Dana, A., \& Satir, M. A. (2009). Countertransference reactions to adolescents with eating disorders: relationships to clinician and patient factors. Eating disorder: the Journal of Treatment and Prevention, 42(6), 511-521.

Espíndola, C. R., \& Blay, S. L. (2009). Percepção de familiares sobre a anorexia e a bulimia: revisão sistemática. Revista de Saúde Pública, 43(4), 707-716.

Ferreira, F. B. G. (2010). Uma compreensão winnicottiana sobre as noções de soma, psique e mente como referência para o entendimento da integração psicossomática. Dissertação de mestrado, Pontifícia Universidade Católica de Campinas, Campinas, SP, Brasil.

Groddeck, G. (1992). Estudos psicanalíticos sobre psicossomática (N. M. Soliz, Trad.). São Paulo: Perspectiva. (Original publicado em 1920).

Hercovici, C., \& Bay, L. (1997). Anorexia e bulimia: ameaças à autonomia. Porto Alegre: Artes Médicas.

Laplanche, J., \& Pontalis, J-B. (2001). Vocabulário da psicanálise 4. ed. (P. Tamen, Trad.). São Paulo: Martins Fontes. (Original publicado em 1982).
McDougall, J. (1984). The "dis-affected" patient: reflections on affect pathology. Psychoanalytic Quarterly, 53(3), 386-409.

McDougall, J. (1991). Teatros do corpo: o psicossoma em psicanálise (P. H. B. Rondon, Trad.). São Paulo: Martins Fontes.

McDougall, J. (1994). Corpo e linguagem: da linguagem do soma às palavras da mente (N. J. P. Franch, Trad.). Revista Brasileira de Psicanálise, 28(1), 75-98.

Miranda, M. R. (2005). Distúrbios da alimentação, anorexia, bulimia e compulsões: história de segredos e paixões. Revista Brasileira de Psicanálise, 39(3), 2734.

Miranda, M. R. (2007). Em busca das palavras perdidas: corpo-carcereiro da mente nos distúrbios alimentares. Ide, 30(45), 28-34.

Morgan, C. M., Vecchiatti, I. R., \& Negrão, A. B. (2002). Etiologia dos trantornos alimentares: aspectos biológicos, psicológicos e sócio-culturais. Revista Brasileira de Psiquiatria, 24(3), 18-23.

Myssior, S. G. (2007). Doenças e manifestações psicossomáticas na infância e adolescência: construindo uma interseção da psicanálise com a pediatria. Tese de doutorado, Universidade Federal de Minas Gerais, Belo Horizonte.

Nava, A. S. (2005). Empatia e grupanálise: uma abordagem integradora. Revista da SPAGESP, 6(2). Recuperado em 18 de agosto, 2011, de http://pepsic.bvsalud.org/scielo.php?pid=S167729702005000200002\&script=sci_arttext

Nunes, M. A., Appolinario, J. C., Galvão, A. L., \& Coutinho W. (2006). Transtornos alimentares $e$ obesidade (2a ed.). Porto Alegre: Artmed.

Peres, R. S. (2006). O corpo na psicanálise contemporânea: sobre as concepções psicossomáticas de Pierre Marty e Joyce McDougall. Psicologia Clínica, 18(1), 165-177.

Peres, R. S., \& Santos, M. A. (2010). O conceito de psicose atual na psicossomática psicanalítica de Joyce McDougall. Revista Brasileira de Psicanálise, 44(1), 99-108.

Rabinor, J. R. (2009). A meditation on life, love and being a therapist: it's not what I expected. Eating Disorder: Journal of Treatment and Prevention, 17(3), 267-272.

Ramalho, R. M. (2005). A escuta da palavra silenciada na anorexia e na bulimia. In: Sales, L. (Org.), Pra que essa boca tão grande? Questões acerca da oralidade. Salvador: Agalma.

Rosa, G. (2006). Grande sertão: veredas. Rio de Janeiro: Nova Fronteira. (Original publicado em 1956).

Santos, M. A. (2006). Sofrimento e esperança: grupo de pacientes com anorexia e bulimia nervosas. Medicina (Ribeirão Preto), 39(3), 386-401.

Sato, M. M. Z. F. (2010). Relações entre transferência e contratransferência na constituição da posição do analista. Dissertação de mestrado, Universidade de Brasília, Brasília, DF.

Sim, L. A., Homme, J. H., Lteif, A. N., Vande Voort, J. L., Schak, K. M., \& Ellingson, J. (2009). Family 
functioning and maternal distress in adolescent girls with anorexia nervosa. International Journal of Eating Disorders, 42(6), 531-539.

Teixeira, L. C. (2006). Um corpo que dói: considerações sobre a clínica psicanalítica dos fenômenos psicossomáticos. Revista Latino-americana de Psicopatologia Fundamental, 6(1), 21-42.

Tierney, S. (2008). The individual within a condition: a qualitative study of young people's reflections on being treated for anorexia nervosa. Journal of the American Psychiatric Nurses Association, 13(6), 368-375.
Winnicott, D. W. (1988). Natureza humana. Londres: Winnicott Trust. (D. Bogomoletz, Trad.). Rio de Janeiro: Imago.

Yin, R. K. (2005). Estudo de caso: planejamento e método (D. Grassi, Trad.). Porto Alegre: Artmed.

Endereço para correspondência:

Daniel Goulart. SGAN 912, Mód. C, Bloco E, apt. 108, Asa Norte, CEP 70790-120, BrasíliaDF, Brasil. E-mail: danielgoulartbr@yahoo.com.br. 